\title{
Bacillus anthracis lethal toxin induces TNF- $\alpha$-independent hypoxia-mediated toxicity in mice
}

\author{
Mahtab Moayeri, ${ }^{1}$ Diana Haines, ${ }^{2}$ Howard A. Young, ${ }^{3}$ and Stephen H. Leppla ${ }^{1}$ \\ ${ }^{1}$ National Institute of Allergy and Infectious Diseases, NIH, Bethesda, Maryland, USA \\ ${ }^{2}$ Veterinary Pathology Section, Pathology and Histotechnology Laboratory, Science Applications International \\ Corporation-Frederick, National Cancer Institute, Frederick, Maryland, USA \\ ${ }^{3}$ Laboratory of Experimental Immunology, Center for Cancer Research, National Cancer Institute, Frederick, Maryland, USA
}

\begin{abstract}
Bacillus anthracis lethal toxin (LT) is the major virulence factor of anthrax and reproduces most of the laboratory manifestations of the disease in animals. We studied LT toxicity in BALB/cJ and C57BL/6J mice. BALB/cJ mice became terminally ill earlier and with higher frequency than C57BL/6J mice. Timed histopathological analysis identified bone marrow, spleen, and liver as major affected organs in both mouse strains. LT induced extensive hypoxia. Crisis was due to extensive liver necrosis accompanied by pleural edema. There was no evidence of disseminated intravascular coagulation or renal dysfunction. Instead, analyses revealed hepatic dysfunction, hypoalbuminemia, and vascular/oxygenation insufficiency. Of 50 cytokines analyzed, BALB/cJ mice showed rapid but transitory increases in specific factors including KC, MCP-1/JE, IL-6, MIP-2, G-CSF, GM-CSF, eotaxin, FasL, and IL-1 $\beta$. No changes in TNF- $\alpha$ occurred. The C57BL/6J mice did not mount a similar cytokine response. These factors were not induced in vitro by LT treatment of toxin-sensitive macrophages. The evidence presented shows that LT kills mice through a TNF- $\alpha$-independent, FasL-independent, noninflammatory mechanism that involves hypoxic tissue injury but does not require macrophage sensitivity to toxin.

J. Clin. Invest. 112:670-682 (2003). doi:10.1172/JCI200317991.
\end{abstract}

\section{Introduction}

Anthrax, the disease caused by Bacillus anthracis, is a worldwide bioterrorism concern. Anthrax toxin, the major virulence factor of this organism, consists of three polypeptides: edema factor (EF), lethal factor (LF), and protective antigen (PA). EF (an adenyl cyclase) and $L F$ (a protease) are toxic only when combined with PA. PA is required for binding and translocation of these enzymatic moieties into target cells (for review, see ref. 1). Lethal toxin (LT), the combination of LF and $\mathrm{PA}$, is sufficient to induce many of the laboratory manifestations of anthrax disease in animal models (2-6).

Early studies suggested that LT killed animals by inducing nonspecific shocklike manifestations and vascular leakage $(2,7)$. Pulmonary edema has also been

Received for publication January 29, 2003, and accepted in revised form June 17, 2003

Address correspondence to: Stephen H. Leppla, Building 30, Room 303, National Institutes of Health, Bethesda, Maryland 20892, USA. Phone: (301) 594-2865; Fax: (301) 480-0326; E-mail: Leppla@nih.gov.

Conflict of interest: The authors have declared that no conflict of interest exists.

Nonstandard abbreviations used: edema factor (EF); lethal factor (LF); protective antigen (PA); lethal toxin (LT); CPt.C-Tnfsf6gld (gld); intraperitoneal(ly) (i.p.); intravenous(ly) (i.v.); phosphotungstic acid hematoxylin (PTAH); heat shock protein 70 (HSP70); heme oxygenase-1 (HO-1); RNase protection assay (RPA); erythropoietin (EPO); extramedullary hematopoiesis (EMH); alanine aminotransferase (ALT); aspartate aminotransferase (AST); disseminated intravascular coagulation (DIC); blood urea nitrogen (BUN); creatinine (CRE). associated with many models of LT-mediated lethality, including the uniquely rapid death of Fischer 344 rats (8). Humans and primates infected by aerosol exposure to spores present pleural effusions as the most common symptom of disease (9-14).

Comparison of mutated $B$. anthracis strains lacking individual toxin components proved that LT is the major virulence factor in mice $(15,16)$. The discovery that inbred mouse strains differed in their relative susceptibility to LT, and that this correlated with the LT sensitivity of their macrophages, implicated this cell in the pathogenesis of LT (17). Later, macrophage depletion experiments in BALB/c mice led Hanna et al. to conclude that macrophage sensitivity was a requirement for LT-mediated toxicity in mice (18). Reports that very low doses of LT induce sensitive macrophages to produce TNF- $\alpha$ and IL- $1 \beta$ in vitro, along with the ability of an IL- 1 antagonist or a mixture of antisera to TNF- $\alpha$ and IL- $1 \beta$ to protect mice from LT challenge, led to the suggestion of a macrophage-dependent endotoxic shock-like death in anthrax (18). This view of macrophage-dependent pathogenesis has been widely cited and has influenced many studies being initiated to identify therapies for treatment of anthrax infections. Thus, many investigators are focusing on anticytokine therapies similar to those used for sepsis.

However, in recent years various laboratories have been unable to induce production of inflammatory cytokines by LT-treated toxin-sensitive macrophages in vitro at the RNA or protein level (19). In fact, the ability of macrophages to produce these factors in 
response to classic stimuli, such as LPS, is actually inhibited by LT treatment (20). This is not surprising, as this protease cleaves major components of three MAPK pathways (20-24). TNF receptor and IL-1 receptor knockout mice are not more resistant to spore challenge than their C57BL/6J parents (25), and LT-susceptible species such as rats (often used for testing of antitoxin therapeutics), as well as humans, harbor toxin-resistant macrophages (26).

Our study investigated the mechanism by which LT kills mice. BALB/cJ "sensitive" and C57BL/6J "resistant" mouse strains (harboring sensitive and resistant macrophages, respectively) were compared at the histopathological and molecular levels. We found a striking contrast between the two strains in early cytokine induction but ultimately similar pathology that did not involve macrophage susceptibility or TNF- $\alpha$. Mortality in LT-treated mice was related to hypoxia-induced liver failure and pleural transudate.

\section{Methods}

Toxin. PA and LF were prepared and purified as previously described (27). Mutant $\mathrm{LF}_{\mathrm{E} 687 \mathrm{C}}$ has been described (28). Mutant $\mathrm{PA}_{\mathrm{D} 683 \mathrm{~A}}$ is a nonbinding PA mutant (M.J. Rosovitz, personal communication). Toxin was diluted in PBS and filter sterilized prior to use. Doses of LT refer to equal amounts of each component (i.e., $100 \mu \mathrm{g} \mathrm{LT}$ is $100 \mu \mathrm{g}$ PA plus $100 \mu \mathrm{g}$ LF). PA and LF were always injected together in the same PBS solution.

Animals. Eight- to ten-week-old male BALB/cJ and C57BL/6J mice were purchased from The Jackson Laboratory (Bar Harbor, Maine, USA). CPt.C-Tnfsfggld (gld) mice (in which mutated, nonfunctional FasL has been backcrossed for 15 generations onto a BALB/c background) were a generous gift from Thomas J. Sayers (National Cancer Institute, Frederick, Maryland, USA). Mice were injected with toxin dilutions, either $1.0 \mathrm{ml}$ intraperitoneally (i.p.) or 10-100 $\mu$ l intravenously (i.v.). Mice were euthanized by $\mathrm{CO}_{2}$ at various times after injection and terminally bled before necropsies were performed. Hematological parameters and differential leukocyte counts were analyzed by the NIH Clinical Center Department of Laboratory Medicine using the Cell-Dyne 3500 automated complete blood count (CBC) analyzer (Abbott Laboratories, Abbott Park, Illinois, USA), and serum was separated for cytokine analyses. Blood chemistry analyses for renal and hepatic function were performed using a Roche/Hitachi 917 analyzer (Roche Diagnostics, Indianapolis, Indiana, USA). Urine, collected at various time points after injection, was analyzed for urea nitrogen and creatinine using a Beckman Coulter Synchron LX20 instrument (Beckman Coulter Inc., Fullerton, California, USA).

Histopathology. A complete necropsy was performed on each mouse. Tissues were fixed by submersion in $10 \%$ neutral-buffered formalin, embedded in paraffin, stained with H\&E, and evaluated by a board-certified veterinary pathologist. In the initial dose-finding experiments using $30,50,100$, and $250 \mu \mathrm{g}$ toxin (i.v. and i.p. routes), more than 40 tissues per animal were evaluated from several animals per dose. The i.v. and i.p. routes produced similar histopathological findings. Based on identification of the most consistently affected tissues, selected tissues were then evaluated in a timed sacrifice study using $100 \mu \mathrm{g} \mathrm{LT}$ (i.p.) in sets of three BALB/cJ and three C57BL/6J mice euthanized at 6, 12, 18, 24, 36, and 48 hours after injection. Control mice injected with PBS or PA alone $(100 \mu \mathrm{g})$ were necropsied at 24 and 48 hours. Mandibular and mesenteric lymph nodes, liver, spleen, lung, heart, thymus, adrenals, and femur with marrow were evaluated. Select sections were stained by phosphotungstic acid hematoxylin (PTAH) or Masson's trichrome. Severity of lesions was qualitatively graded on a four-point scale: minimal, mild, moderate, and marked. Immunohistochemistry was performed on select tissues: mandibular and mesenteric lymph nodes, thymus, liver, spleen, and lung. Antibodies to CD45R (Pharmingen, San Diego, California, USA), CD3 (DAKO Corp., Carpinteria, California, USA), and the macrophage surface antigen F4/80 (Caltag Laboratories Inc., Burlingame, California, USA) were used on formalinfixed tissues. Vectastain Elite kits (Vector Laboratories Inc., Burlingame, California, USA) were used for stain visualization, and diaminobenzidine (DAB) was the chromagen. Antibodies against murine heat shock protein 70 (HSP70) (Santa Cruz Biotechnology Inc., Santa Cruz, California, USA), VEGF (Santa Cruz Biotechnology Inc.), and heme oxygenase-1 (HO-1) (StressGen Biotechnologies Corp., Victoria, British Columbia, Canada) were used on $4 \%$ paraformaldehyde-fixed tissues. The EnVision kit (DAKO Corp.) with DAB was used. In separate experiments, spleens were extracted and immediately placed in RNAlater (Ambion Inc., Austin, Texas, USA) followed by RNA extraction using Trizol (Life Technologies Inc., Rockville, Maryland, USA), for use in the RNase protection assays (RPAs) described below. Alternatively, spleens were placed in $4 \%$ paraformaldehyde for in situ staining, described below. For Western blotting of tissue antigens, livers were harvested and homogenized in RIPA buffer ( $1 \times$ PBS, $1 \%$ Nonidet P- 40 , $0.5 \%$ sodium deoxycholate, $0.1 \%$ SDS) using TissueTearor (BioSpec Products Inc., Bartlesville, Oklahoma, USA). Homogenates were spun, and protein was quantified using the BCA kit (Pierce Chemical Co., Rockford, Illinois, USA) prior to SDS-PAGE and immunoblotting. Cells. RAW264.7 macrophage cells were cultured in DMEM with $10 \%$ FCS. Peritoneal macrophages were elicited by injection of $2 \mathrm{ml}$ of $4 \%$ Brewer modified thioglycolate (Becton Dickinson Microbiology Systems, Cockeysville, Maryland, USA) 72 hours prior to harvesting by peritoneal lavage. Monocytes were extracted from mouse peritonea by lavage without prior thioglycolate injection. Mononuclear cells were attached to plastic and washed with medium prior to culture.

RPA. The Multiprobe RNAse Protection Assay (RPA) (Pharmingen) was performed with some modification. Probes were synthesized with ${ }^{33} \mathrm{P}-\mathrm{UTP}(70-80 \mu \mathrm{Ci}$ per full reaction) using the Pharmingen In Vitro Transcrip- 

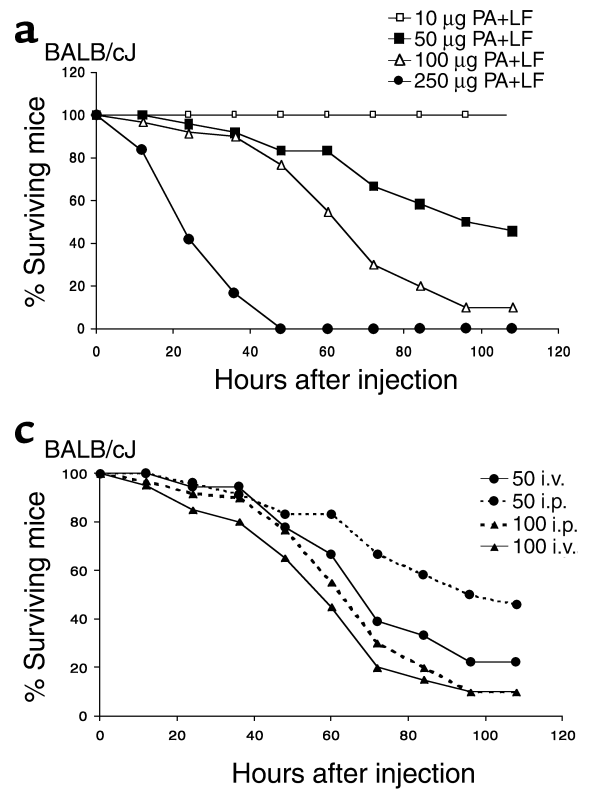

Figure 1

LT toxicity in inbred mice. ( $\mathbf{a}$ and $\mathbf{b}$ ) Comparison of four doses of PA plus LF in BALB/c) (a) and C57BL/6J (b) mice. Mice were injected i.p. with $1 \mathrm{ml}$ of toxin in PBS. Results are based on $n=12$, $n=24, n=60$, and $n=12$ for $10 \mu \mathrm{g}, 50 \mu \mathrm{g}, 100 \mu \mathrm{g}$, and $250 \mu \mathrm{g}$ of each toxin component. (c) Comparison of i.p. and i.v. routes of injection in the BALB/cJ mouse. Results are based on $n=18, n=24$, $n=60$, and $n=20$ for $50 \mu$ g i.v., $50 \mu$ g i.p., $100 \mu$ g i.p., and $100 \mu \mathrm{g}$ i.v. of each toxin component. The differences in i.p. and i.v. survival curves at both 50 and $100 \mu \mathrm{g}$ are not statistically significant by the log-rank test ( $P=0.0807$ and 0.553 , respectively). The difference between the $50-\mu \mathrm{g}$ i.p. curve and both $100-\mu \mathrm{g}$ curves is statistically significant $(P=0.0013$ and $P=0.0002)$. (d) Data from $\mathbf{a}$ and $\mathbf{b}$ for the $100-\mu \mathrm{g}$ dose injected i.p., presented to allow direct comparison of the single selected dose used in all further experiments.

tion kit. Following incubation, yeast tRNA and EDTA were added. The reaction was placed on G25 MicroSpin columns (Amersham Pharmacia Biotech, Piscataway, New Jersey, USA), and the probe was purified by centrifugation for 2 minutes at $750 \mathrm{~g}$. The probe was added at $0.5 \times 10^{6}$ to $1.0 \times 10^{6} \mathrm{cpm}$ to each tissue RNA sample in a final hybridization volume of $10-20 \mu \mathrm{l}$ (at least 50\% Pharmingen hybridization buffer). For RNase inactivation, a master cocktail, containing $200 \mu \mathrm{l}$ Ambion RNase inactivation reagent (Ambion Inc.), $50 \mu \mathrm{l}$ ethanol, $5 \mu$ g yeast tRNA, and $1 \mu \mathrm{l}$ Ambion GlycoBlue coprecipitate (Ambion Inc.) per RNA sample, was used to precipitate the protected RNA. After addition of the individual RNase-treated samples to $250 \mu \mathrm{l}$ of the inactivation/precipitation cocktail, the samples were mixed well, placed at $-70^{\circ} \mathrm{C}$ for 30 minutes, and centrifuged at $16,000 \mathrm{~g}$ for 15 minutes at room temperature. The supernatants were decanted, a sterile cotton swab was used to remove excess liquid, and the pellet was resuspended in $3 \mu \mathrm{l}$ of Pharmingen sample buffer.

Cytokine expression. ELISA kits for IL-1 $\beta$, IL-6, IL-10, MCP-1/JE, KC, GM-CSF, FasL, G-CSF, eotaxin, LIF (R\&D Systems Inc., Minneapolis, Minnesota, USA), MIP-2 (IBL, Fujioka-city, Japan), and TNF- $\alpha$ (Chemicon International Inc., Temecula, California, USA) were used for assessment of chemokine and cytokine protein levels in serum.
Erythropoietin measurements. The human erythropoietin (EPO) immunoassay kit (R\&D Systems Inc.) can be used for mouse EPO measurements and was used to assess serum levels of EPO at various times after toxin injection.

In situ bybridization. In situ hybridization was performed by a previously published protocol originally developed for detection of viral RNA (29). Tissue sections were hybridized with ${ }^{35} \mathrm{~S}$-labeled riboprobes in the sense and antisense configurations transcribed from a 1.0-kb KC gene insert. KC cDNA was cloned via RT-PCR into the Topo-TA cloning vector pCRII-TOPO (Invitrogen Corp., Carlsbad, California, USA). The plasmid was linearized before transcription with either T7 polymerase or SP6 polymerase. Probes were truncated by alkaline hydrolysis to about $200 \mathrm{bp}$. Following hybridization, slides were imaged in a Fuji 5000 PhosphorImager (Fuji Corporation, Tokyo, Japan). Subsequently, the slides were dipped in radiographic emulsion, exposed for 5 days, developed, and stained with H\&E.

\section{Results}

\section{LT-induced lethality in inbred mice}

The effects of LT dose and route of administration were examined in $\mathrm{BALB} / \mathrm{cJ}$ and $\mathrm{C} 57 \mathrm{BL} / 6 \mathrm{~J}$ mice, which have toxin-sensitive and -resistant macrophages, respectively (30). Mortality consistently occurred earlier and more often in the BALB/cJ mice (Figure 1, a and b). Since both i.p. and i.v. routes produced similar survival curves at the $100-\mu \mathrm{g}$ dose (Figure 1c), i.p. administration of this dose was used for subsequent experiments. At $100 \mu \mathrm{g}$ i.p., $\mathrm{BALB} / \mathrm{cJ}$ mice displayed severe malaise by 48 hours, with $50 \%$ dying by 60 hours. By comparison, at 48 hours, C57BL/6J mice showed minimal to no malaise, and few of these mice died before 60 hours. However, $40 \%$ of C57BL/6J mice were dead by 96 hours (Figure 1d).

\section{LT effects on hematological parameters}

LT induced a rapid reduction in the number of circulating mononuclear cells in the BALB/cJ mice, with almost complete depletion by 10 hours after toxin administration (Figure $2 \mathrm{a}$ ) and no evidence of recovery. While the number of circulating monocytes initially 
decreased in the $\mathrm{C} 57 \mathrm{BL} / 6 \mathrm{~J}$ mice, there was rapid recovery to higher than initial levels after 10 hours (Figure 2a). Interestingly, the marked depletion of circulating mononuclear cells was not paralleled by depletion of fixed tissue macrophages (see below). There was a rapid five- to tenfold increase in circulating neutrophils, with numbers remaining high over 48 hours in both strains (Figure 2b). A drop in platelet levels (thrombocytopenia) occurred in both strains in the first 12 hours and was more marked in the BALB/cJ mice (Figure 2c). However, there were large variations in platelet numbers in all groups harvested at 24 hours or longer after LT administration, and many terminally ill animals did not display thrombocytopenia. Thus, thrombocytopenia was not consistently associated with terminal illness. There were no changes in circulating $B$ and $T$ lymphocyte numbers (data not shown).

\section{Histopathological and physiological findings in LT-treated mice}

Summary of macroscopic findings. These findings are cumulative from multiple experiments with a total pool of six to twelve animals per time point. No significant gross lesions were observed in control mice. Significant observations in the BALB/cJ mice included the following: multiple tan or dark red liver foci in $90 \%$ of the mice at 18 hours and later time points; mottled "nutmeg" liver in 14 of 30 at 60 hours; discolored dark $\mathrm{red} / \mathrm{black}$ feces in the small and large intestines in 50\% at 18 hours and later time points; dark splenic foci, only at 18 hours; darkened paws and black toes in 19 of 60 at time points past 12 hours; pleural cavity fluid $(1-3 \mathrm{ml})$ in $60 \%$ at 48 hours and in $90 \%$ by 60 hours; and ascites (i.e., peritoneal cavity fluid; $3-5 \mathrm{ml}$ ) in 50\% at 60 hours. C57BL/6J mice developed similar lesions but at later times: tan to red liver foci in $5 \%$ of animals at 48 hours and $50 \%$ by 72 hours; mottled "nutmeg" liver in 12 of 30 at 96 hours; discolored feces in $20 \%$ at

\section{Figure 2}

LT effects on circulating monocytes, neutrophils, and platelets. Graphs show circulating monocyte (a), neutrophil (b), and platelet (c) levels in response to LT treatment as a percentage of untreated controls. Values are the mean of the percentage change in two to eight individual pooled experiments using both i.p. and i.v. treated mice at doses of $50 \mu \mathrm{g}, 100 \mu \mathrm{g}$, and $250 \mu \mathrm{g} \mathrm{LT}$, based on groups of two to four mice per time point. Values were calculated as the percentage change in cell number relative to a PBS-treated control group (two to four mice per experiment). Absolute control cell numbers differed in each experiment. Error bars indicate SD for the mean percentage change. Unpaired $t$ test analysis indicates that differences in curves in a are statistically significant at 18,24 , and 36 hours $(P=0.008, P<0.0001$, and $P<0.0001$, respectively). In $\mathbf{b}$, differences in the two strains are only significant at 10 and 12 hours ( $P=0.002$ and $P=0.004$, respectively). In c, differences in the two strains are not significant at any point. In a, differences relative to 0 hours are statistically significant at all times past 6 hours in $\mathrm{BALB} / \mathrm{cJ}$ and at $6,10,12$, and 36 hours in C57BL/6J. In b and $\mathbf{c}$, differences relative to 0 hours are statistically significant beyond 10 hours in BALB/CJ and beyond 24 hours in C57BL/6J.
96 hours; pleural cavity fluid in $90 \%$ at 96 hours; and ascites in $30 \%$ at 96 hours. Darkened extremities and splenic foci were not seen in the C57BL/6J mice.

Microscopic findings and chemical analyses. No significant lesions were noted in the control mice. In mice receiving LT, lesions occurred primarily in the spleen, bone marrow, and liver, with more minor changes in a few other tissues, as described below.

Spleen. At 6 and 12 hours after injection, BALB/cJ mice treated with LT showed mild to moderate individual cell (apoptotic-like) death of myelogenic cells in the splenic red pulp (Figure 3, b and c) accompanied by a moderate decrease in normal extramedullary hematopoiesis (EMH), including megakaryocytes. Minimal to mild individual (apoptotic-like) death of lymphoid cells was present in the splenic white pulp. At 18 hours, mild to moderate hemorrhage developed in both the red and the white pulp (Figure 3, $\mathrm{d}$ and e). A turnaround occurred by 24-36 hours and continued through 48 hours (Figure 3f), with a decrease in splenic necrosis, resolution of the hemorrhage, and recovery of EMH with a left shift (increase in percentage of immature versus mature forms, primarily in the granulocytic series). The $\mathrm{C} 57 \mathrm{BL} / 6 \mathrm{~J}$ mice, in contrast, showed no

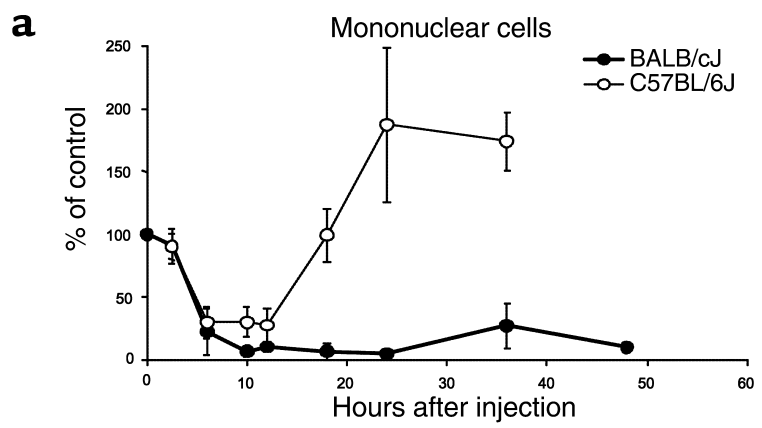

b

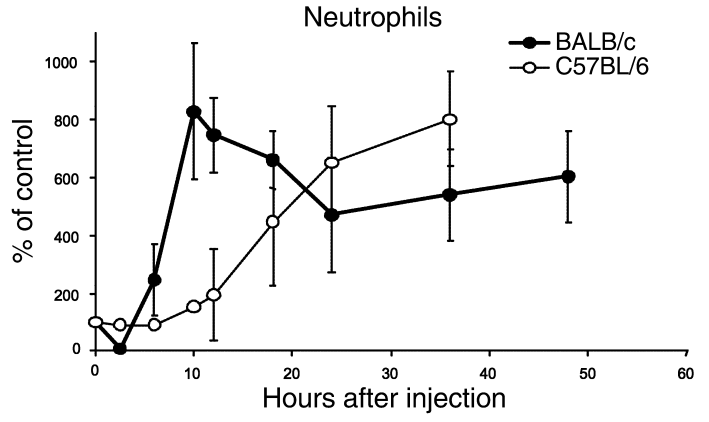

C

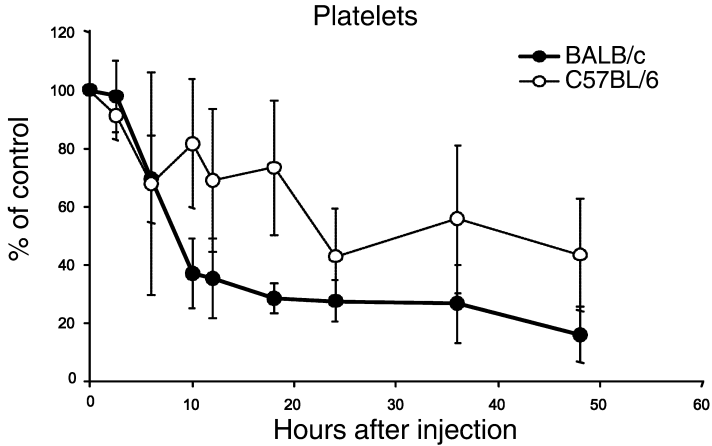




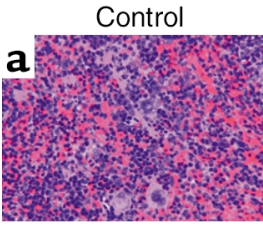

$18 \mathrm{~h}$

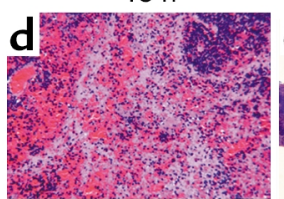

$6 \mathrm{~h}$

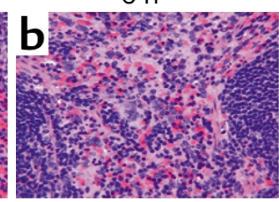

$18 \mathrm{~h}$

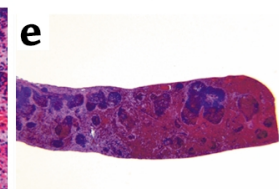

$12 \mathrm{~h}$

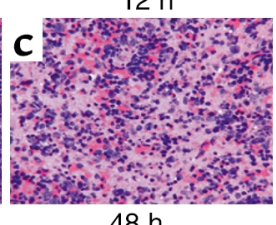

$48 \mathrm{~h}$

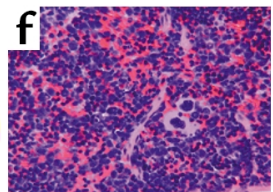

Figure 3

Histopathological analysis of LT-treated BALB/cJ mouse spleen. (a) Red pulp from PA-injected (48 hours) control. $40 \times$ objective. (b) Individual cell death in red pulp with relative sparing of white pulp at 6 hours after LT treatment. $40 \times$ objective. (c) Advanced necrosis in red pulp at 12 hours. $40 \times$ objective. (d) Hemorrhage in red and white pulp at 18 hours. $20 \times$ objective. (e) Hemorrhage in red and white pulp at 18 hours. $2 \times$ objective. (f) Resolution of cell death with restoration of extramedullary hematopoiesis $(\mathrm{EMH})$ at 48 hours. $40 \times$ objective. Dosage was $100 \mu \mathrm{g}$ PA (control) or $100 \mu \mathrm{g}$ LT.

changes in the spleen, with the exception of a minimal increase in EMH only at 18 hours (data not shown).

Bone marrow. At 6 and 12 hours after injection, $\mathrm{BALB} / \mathrm{cJ}$ mice showed mild to moderate individual cell death throughout the femoral bone marrow (Figure 4b). Severity of the apoptotic-like bodies peaked at 18 hours (Figure 4c). By 24 hours, mild, diffuse, infarction-like necrosis, compatible with hypoxia, was evident in the metaphyseal marrow of the femur. Neither the diaphyseal nor the epiphyseal marrow showed this overt necrosis. By 48 hours, necrosis in the metaphyseal bone marrow was marked (Figure 4, e and f). Individual cell death in the diaphyseal marrow was also noted to a mild degree. The C57BL/6J mice showed similar pathologies in the bone marrow at later time points and with lower incidence and severity. Mild metaphyseal marrow necrosis first occurred at 36 hours and became moderate at 48 hours in the C57BL/6J mice (data not shown).

Liver. BALB/cJ mice developed liver lesions ranging from small hemorrhagic infarcts to large areas of centrilobular coagulative necrosis by $18-24$ hours after LT injection (Figure $5 \mathrm{~b}$ ). Rarely, mild to moderately dilated vascular spaces with poorly formed acellular thrombi were associated with the necrosis (Figure 5c). No significant amount of fibrin was evident in these poorly organized thrombi (PTAH stain) (data not shown). Liver necrosis increased in incidence and severity at 36 hours and continued with no recovery through 48 hours (Figure $5 \mathrm{~d}$ ). The presence of hemorrhagic infarcts and centrilobular coagulative necrosis without significant fibrin clots was compatible with hypoxia due to blood stasis and/or decrease in venous drainage rather than due to arterial thrombosis. Similar liver necrosis was noted at a later time point (48 hours) with lower severity (minimal to mild) in the C57BL/6J mice.
Severity progressed to marked by 72 hours and 96 hours in the C57BL/6J mice (data not shown). Analysis of blood chemistry revealed significant increases in the liver-dysfunction indicators serum alanine aminotransferase (ALT) and aspartate aminotransferase (AST) in a majority of the LT-treated mice at time points after 48 hours (Figure 6, a-d). Liver dysfunction was also indicated by decreased serum albumin levels noted in both mouse strains in response to toxin over time (Figure 6, e and $\mathrm{f}$ ).

Thymus and heart. The BALB/cJ mice had minimal lymphoid cell death in the thymic cortex and medulla at 6 hours, without significant change through 24 hours. At 36 hours, T lymphocyte death was moderate (probably secondary to the stress of major organ necrosis/failure), progressing to marked levels at 48 hours, with a resultant decrease in cortical depth (data not shown). Minimal coagulative necrosis was noted in the heart, with occasional mild cardiac dilatation at 48 hours in a few animals (data not shown). Blood chemistry analysis, however, indicated that the serum creatinine kinase level (an indicator of myocardial dysfunction) was elevated up to fivefold in only $10 \%$ of toxin-treated mice of both strains at later time points (data not shown).

Other observations. Extensive pleural and peritoneal fluid accumulation with progression of malaise state was noted in both mouse strains. Despite the relatively high incidence of pleural fluid accumulation noted grossly, light microscopy did not reveal any lesion in the lung, suggesting that permeability alterations did not result from overt tissue damage. Neither H\&E nor PTAH staining of lung revealed any evidence of capillary thrombosis or fibrin clots as seen with the disseminat-
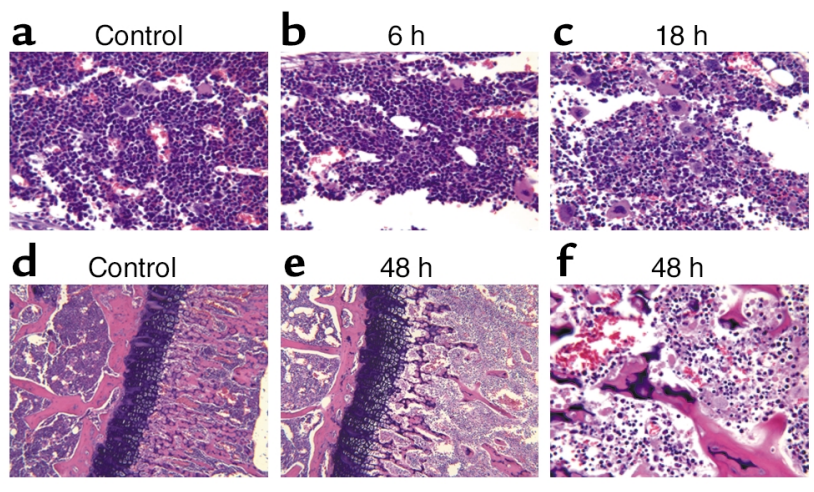

\section{Figure 4}

Histopathological analysis of LT-treated BALB/c) bone marrow. (a) Diaphyseal marrow from PA-treated (48 hours) control. $40 \times$ objective. (b) A mild degree of individual cell death in diaphyseal marrow at 6 hours after LT treatment. $40 \times$ objective. (c) A moderate degree of individual cell death in diaphyseal marrow at 18 hours. $40 \times$ objective. (d) Metaphyseal (right) and epiphyseal (left) marrow in PAtreated (48 hours) control. 10x objective. (e) Necrosis of metaphyseal marrow (right) with sparing of epiphyseal marrow (left) at 48 hours after LT treatment. 10× objective. (f) Necrosis of metaphyseal bone marrow at 48 hours. $40 \times$ objective. Dosage was $100 \mu \mathrm{g}$ PA (control) or $100 \mu \mathrm{g}$ LT. 

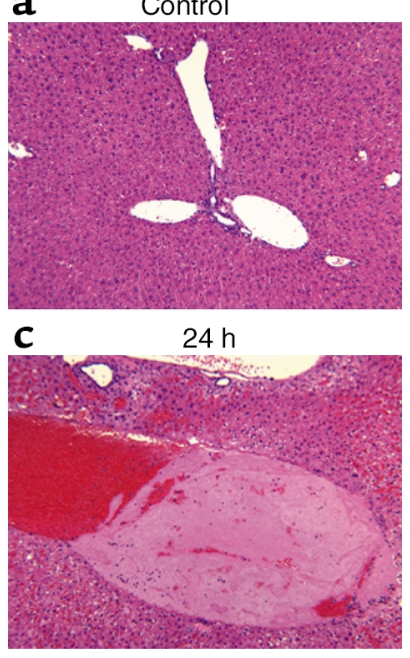

b

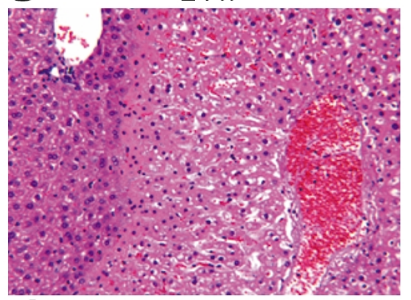

d

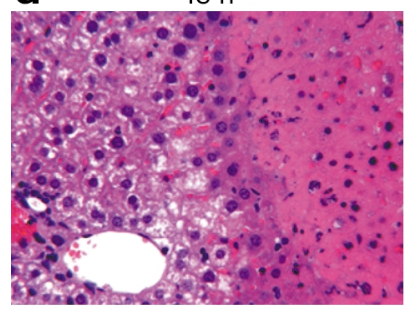

ed intravascular coagulation (DIC) that is commonly associated with classical macrophage/TNF- $\alpha$-driven endotoxic shock. Because hypoalbuminemia caused by liver damage can directly lead to leakage of fluid from vessels due to low plasma colloid osmotic pressure, we hypothesized that this effect might contribute to the vascular leakage observed in the LT-treated mice. Analysis of peritoneal and pleural fluids from premortem mice revealed cell-free, clear, straw-colored fluids with lower albumin concentrations relative to serum (Figure 6 , e and $\mathrm{f}$. This albumin ratio is used to differentiate between exudates resulting from inflammationinduced increased capillary permeability and transudates resulting from altered intravascular hydrostatic/oncotic pressure. The fluids in LT-treated mice appear to be the latter, supporting a contribution of low colloid osmotic pressure to the fluid accumulation seen in LTtreated animals.

$\mathrm{H} \& \mathrm{E}$ and PTAH staining of kidneys, the other organ often affected in cytokine-mediated shock, did not reveal any lesions, nor evidence of capillary thrombosis. Evidence that renal failure did not occur in LT-treated mice was further provided by analysis of blood urea nitrogen (BUN) and serum creatinine (CRE). Serum CRE is the more specific determinant of renal function, because, unlike BUN levels, serum CRE levels are not affected by protein metabolism or the hydration status. No sig-

\section{Figure 6}

Serum ALT ( $\mathbf{a}$ and $\mathbf{b}$ ), AST (c and $\mathbf{d}$ ), and albumin (e and f) levels in LT-treated mice. ALT, AST, and albumin were analyzed from serum at 18, 24, 48, 60, 72 (BALB/cJ and $\mathrm{C} 57 \mathrm{BL} / 6 \mathrm{~J})$, and 96 hours $(\mathrm{C} 57 \mathrm{BL} / 6 \mathrm{~J})$, as well as from premortem mouse peritoneal $(P)$ and lung $(L)$ fluids of both strains. Intraperitoneal dosage was $100 \mu \mathrm{g}$ LT. Each data point represents one mouse. The number of sera analyzed at each time point ranged from three to eight.

\section{Figure 5}

Histopathological analysis of LT-treated BALB/cJ liver. (a) Liver from PA-injected (48 hours) control. 10× objective. (b) Centrilobular coagulative necrosis (right) with normal liver and sparing of portal region (upper left) at 24 hours after LT treatment. 20x objective. (c) Poorly formed thrombus at 24 hours. $10 \times$ objective. (d) Advanced liver necrosis (right) with continued sparing of portal region (lower left) at 48 hours. 40× objective. Dosage was $100 \mu \mathrm{g}$ PA (control) or $100 \mu \mathrm{g}$ LT.

nificant change in CRE was seen in either mouse strain at any time after LT treatment, with only 2 of 55 mice falling outside the normal $0.1-1.1 \mathrm{mg} / \mathrm{dl}$ serum CRE range for mice (Supplemental Figure 1; www.jci.org/ cgi/content/full/112/5/670/DC1). Overall results indicated that there were no statistically significant changes in BUN levels in LT-treated mice, despite a small number of outliers ( 3 of $27 \mathrm{BALB} / \mathrm{cJ}$ ) and 4 of 28 C57BL/6J mice) (Supplemental Figure 1). These mice may not represent biologically relevant events, since BUN changes independent of CRE are not an indication of renal dysfunction and often reflect altered metabolism or urination. No significant changes in the levels of urea nitrogen and CRE were seen in urine from LT-treated animals collected every 12 hours after injection (data not shown).

There was no evidence of neutrophil margination in the blood vessels of any examined tissue. Even areas of extensive tissue necrosis, such as the liver, had minimal to no associated inflammatory cells. Immunohistochemical staining for macrophages showed only
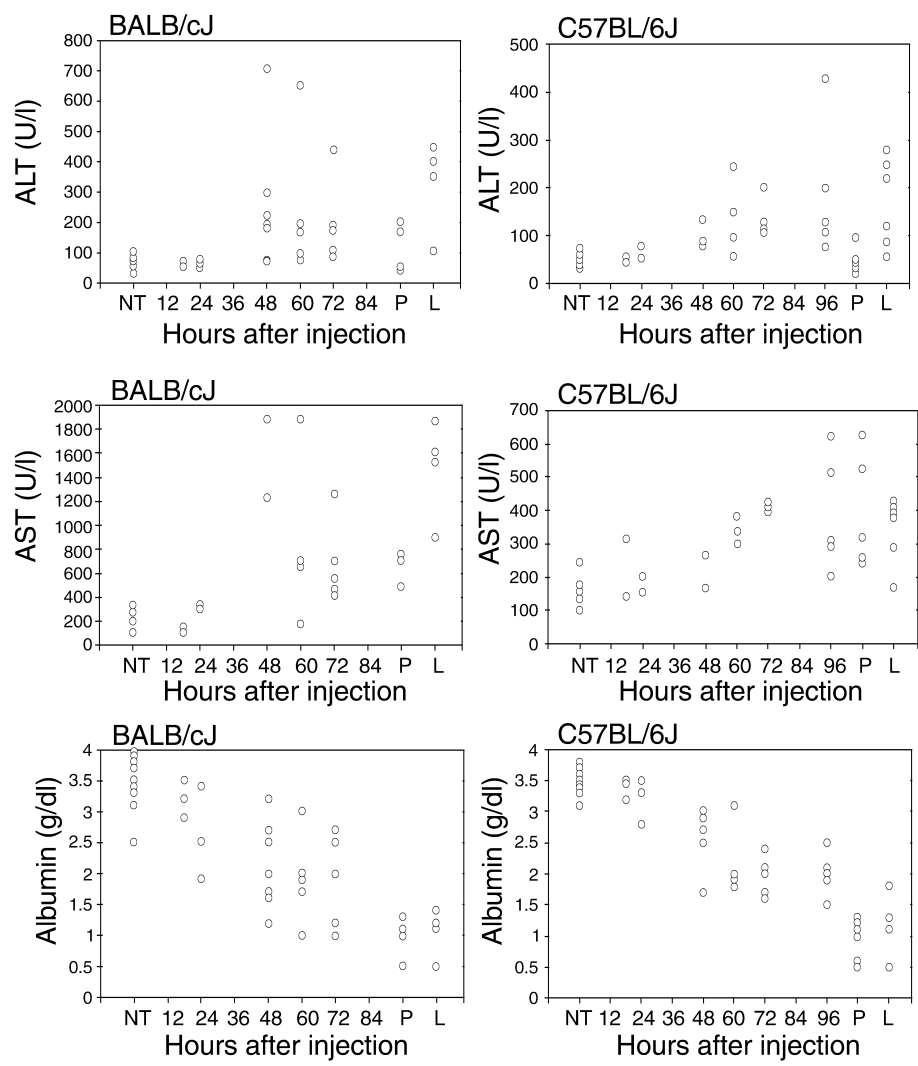

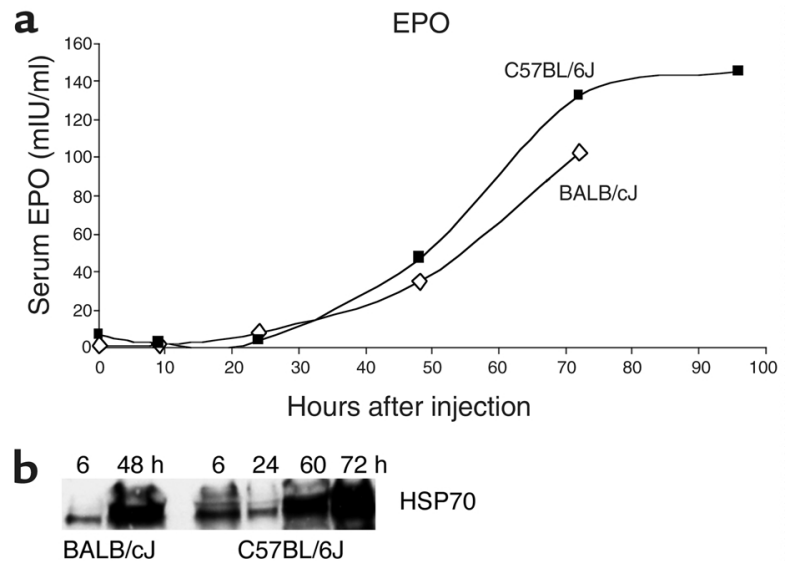

Figure 7

LT-induced hypoxia. (a) Mice were injected i.p. with $1.0 \mathrm{ml}$ of PBS or $100 \mu \mathrm{g}$ LT. Serum EPO measurements at each time point represent averages of values assessed for two samples, with each sample representing sera pooled from three mice. The exception is the 72-hour time point for $B A L B / c J$, which represents measurement of one sample composed of pooled sera from three mice. (b) Liver extracts from $\mathrm{BALB} / \mathrm{cJ}$ or C57BL/6J mice treated i.p. with $100 \mu \mathrm{g} \mathrm{LT}$ for $6,24,60$, and 72 hours were analyzed for HSP70 levels by Western blot.

a minimal decrease in fixed-tissue macrophages in the lymph nodes, spleen, and liver at the various time points (Supplemental Figure 2; www.jci.org/cgi/content/full/112/5/670/DC1), indicating that the effect of LT on these cells was different from its effect on circulating monocytes. Immunohistochemistry also showed minimal to no decrease in $\mathrm{T}$ cell populations in spleen, liver, and lung (data not shown). A minimal to mild increase in B cells was noted, particularly at later time points in the liver and lung (data not shown). Despite the presence of red intestinal contents in some mice, there was no evidence of intestinal hemorrhage or necrosis by light microscopy. Hemorrhage (often associated with DIC) was also not noted in any other organ, with the exception of the BALB/cJ spleens at 18 hours. Limbs macroscopically noted to be discolored exhibited congestion and edema, without evidence of thrombi or inflammation.

In summary, crisis in the mice appeared to relate to liver necrosis resulting from hypoxia. Oxygenation insufficiency and systemic hypoxia may be the result of vascular permeability alterations, reflected by the accumulation of pleural and peritoneal cavity fluid and gross edema in extremities, or, alternatively, may be the initiating factor for the observed vascular leakage. Metaphyseal bone marrow necrosis observed in LTtreated mice also supports tissue injury due to oxygenation insufficiency.

\section{LT induction of hypoxia}

To further investigate LT-induced hypoxic injury, EPO, HO-1, and HSP70 were used as markers of hypoxia (31-34). Induction of these genes by a similar stimulus may differ based on mouse-strain differ- ences. Therefore, response levels do not provide a quantitative measure of illness, extent of vascular collapse, or progression of hypoxic state between different mouse strains. Their induction, however, is a clear indicator of a hypoxic response. Analysis of sera from LT-treated mice showed remarkable increases in EPO in both strains (Figure 7a), which may reflect systemic hypoxia. These data also support the previous observation that kidneys are not affected in LT-treated mice, since the kidney is a major source of EPO, and renal dysfunction manifests as a decrease in EPO production. Immunostaining of liver showed a slight increase in HO-1 in hepatocytes and a marked increase in Kupffer cells at 48 hours in both strains (Supplemental Figure 3). Western blot analysis for HSP70 revealed an impressive induction in the liver (Figure $7 \mathrm{~b}$ ). These results demonstrate a hypoxic state induced in mice by LT treatment.

LT induction of cytokines and chemokines in mice

To investigate the potential involvement of cytokines in LT-mediated pathogenesis (18), the production of numerous factors was screened for by RPA analysis: IL-4, IL-5, IL-3, IL-13, IL-9, IL-2, IL-12, IL-10, IL-1 $\alpha$, IL-1 $\beta$, IL-1RA, IL-18, IL-6, MIF, Ltn, eotaxin, RANTES, MIP-1B, MIP-2, MCP-1/JE, IP10, C10L, KC, LIF, IL-7, M-CSF, SCF, IFN- $\gamma$, FasL, caspase-8, Fas, FADD, FAP, FAF, TRAIL, TNFRp55, TRADD, RIP, TNF- $\beta$, LTB, TNF- $\alpha$, and TGF- $\beta 1$. Three spleens per

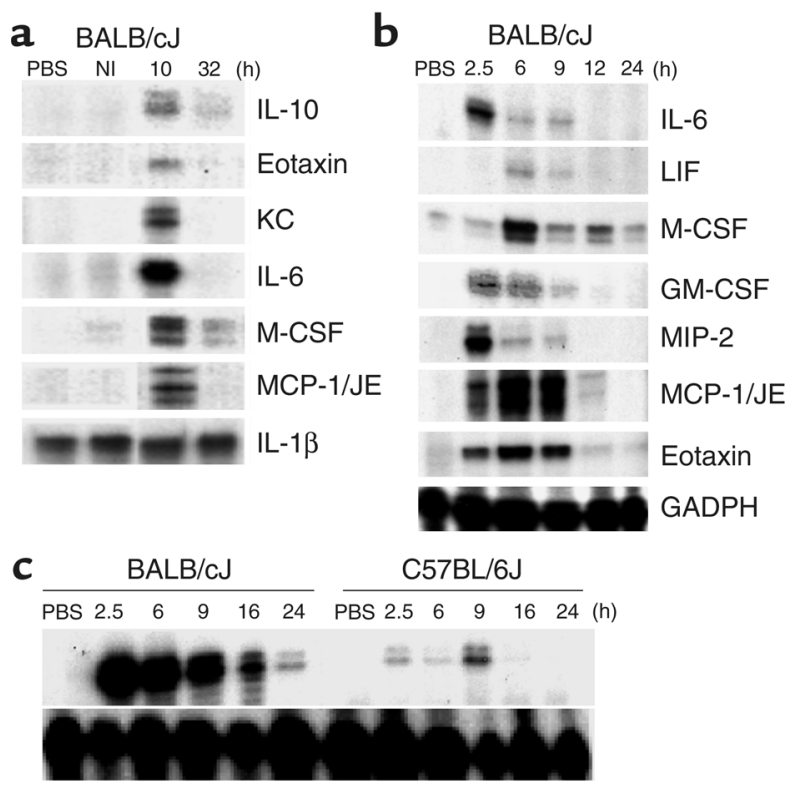

Figure 8

RPA analysis of LT-treated mice. (a) BALB/cJ mice were treated i.p. with $100 \mu \mathrm{g} L T$, and spleens were obtained after 10 or 32 hours. PBSinjected and noninjected (NI) controls were included for comparison. (b) A similar experiment with additional time points. A PBSinjected control was included for comparison. (c) Comparison of $\mathrm{BALB} / \mathrm{cJ}$ and $\mathrm{C} 57 \mathrm{BL} / 6 \mathrm{~J}$ spleen KC RNA levels at various times after i.p. injection of $100 \mu \mathrm{g}$ LT. GADPH was used as a control for equal RNA loading in all lanes. 
Table 1

Spleen RNA changes in response to LT

\begin{tabular}{|c|c|c|}
\hline Factor & $\mathrm{BALB} / \mathrm{c}$ RNA & C57BL/6 RNA \\
\hline Eotaxin & $\uparrow$ & $\leftrightarrow$ \\
\hline Fas & $\uparrow$ & $\leftrightarrow$ \\
\hline FasL & $\uparrow$ & $\leftrightarrow$ \\
\hline G-CSF & $\uparrow$ & $\leftrightarrow$ \\
\hline GM-CSF & $\uparrow$ & $\leftrightarrow$ \\
\hline IL-1 $\alpha$ & $\leftrightarrow^{\mathrm{A}}$ & $\uparrow_{A}$ \\
\hline IL-1 $\beta$ & $\leftrightarrow^{\mathrm{B}}$ & $\uparrow c$ \\
\hline IL-6 & $\uparrow$ & $\leftrightarrow$ \\
\hline IL-7 & $\downarrow^{A}$ & 1 \\
\hline IL-10 & $\uparrow c$ & $\leftrightarrow$ \\
\hline IL-15 & $\leftrightarrow$ & $\uparrow$ \\
\hline IL-18 & $\downarrow \mathrm{B}$ & $\leftrightarrow$ \\
\hline IP10 & $\uparrow$ & $\leftrightarrow$ \\
\hline $\mathrm{KC}$ & $\uparrow$ & $\uparrow \mathrm{D}$ \\
\hline LIF & $\uparrow c$ & $\leftrightarrow$ \\
\hline MCP-1 & $\uparrow$ & $\leftrightarrow$ \\
\hline M-CSF & $\uparrow$ & $\uparrow \mathrm{D}$ \\
\hline MIP-2 & $\uparrow$ & $\leftrightarrow$ \\
\hline RANTES & $\downarrow^{A}$ & ND \\
\hline
\end{tabular}

Changes noted are for 2.5-6 hours or 2.5-12 hours after toxin injection. $\leftrightarrow$, No change; $\uparrow$, upregulated; $\downarrow$, downregulated; I, inconclusive; ND, no data available. ${ }^{A}$ Not tested at the protein level. B Increase in levels observed at the protein level. ${ }^{C}$ Result is not seen at the protein level. ${ }^{D}$ The change in C57BL/6 mice was very low.

time point were harvested from 2.5 hours to 72 hours (BALB/cJ) or 2.5 hours to 96 hours $(\mathrm{C} 57 \mathrm{BL} / 6 \mathrm{~J})$ after $\mathrm{LT}$ injection. Cytokine and chemokine expression was not altered between 24 hours and 96 hours; however, a number of factors were induced between 2.5 and 24 hours, primarily in the BALB/cJ mouse. Representative RPA gels are shown in Figure 8, and data from these and other gels are summarized in Table 1. Factors that showed altered expression in the $\mathrm{BALB} / \mathrm{cJ}$ mice, as early as 2.5 hours, included IL-10, GM-CSF, IL-6, eotaxin, MIP-2, MCP-1/JE, KC, LIF, and M-CSF (Figure 8, a and b). The induction of the $\mathrm{KC}$ gene was notably rapid and dramatic in the $\mathrm{BALB} / \mathrm{cJ}$ spleen samples (Figure 8c). The C57BL/6J mouse did not show alterations in the majority of these factors, with the exception of a slight early induction of $\mathrm{KC}$ and M-CSF. IL-15 was induced only in the $\mathrm{C} 57 \mathrm{BL} / 6 \mathrm{~J}$ mouse (Table 1 ). Although previous studies have reported production of IL- $1 \beta$ and TNF- $\alpha$ by macrophages and implicated these cytokines in an endotoxic shock-like death mechanism (18), our analysis showed no induction of IL- $1 \beta$ or TNF- $\alpha$ at the RNA level. In the earlier studies, done in cultured macrophages, LT preparations were produced in Escherichia coli, and trace amounts of endotoxin may have been responsible for the cytokine response. Our findings detected no evidence of classic Th1/Th2 cytokine responses or TNF- $\alpha$-based inflammatory cascades in either strain. Analyses performed on spleens from mice injected by the i.v. route or with lower toxin doses gave similar results (data not shown). Factors listed above that do not appear in Table 1 showed no changes at the RNA level.

Protein profiles analyzed from sera by ELISA (Figure 9) closely paralleled RPA results from spleen, with a few exceptions. Antiinflammatory IL-10 and proinflammatory LIF, which showed moderate RNA induction (Figure 8, a and b), were not detected at the protein level (data not shown). Also, IL-1 $\beta$, which was not induced at the RNA level in spleen, was detected in serum of toxintreated BALB/cJ mice. IL- $1 \beta$ may have been induced in other organs, or simply released from intracellular stores. The C57BL/6J mice showed only a slight KC response, which was also noted at the RNA level (Figure $8 c)$. By 24 hours, all factors except MCP-1/JE and G-CSF had declined to base-line levels. These latter two factors returned to base line by 48 hours. The induction of TNF- $\alpha$ was not observed in either strain at the protein level (Figure 9).

To test specificity of cytokine induction, additional mice were injected i.p. with $100 \mu \mathrm{g}$ of PA, LF, mutant PA (D683A substitution) that does not bind to receptor (M.J. Rosovitz, personal communication), mutant LF (E687C substitution) that does not have proteolytic activity (28), a combination of mutant PA and mutant LF, boiled LF, or BSA. Both PA and LF induced KC, MCP-1/JE, and G-CSF transiently at 2.5 hours, but at $25-50 \%$ of the LT-induced levels, and induction was at or below that in PBS-treated controls by 6 hours (data not shown). Since BSA, mutant toxins, and boiled LF also induced these three factors, induction was interpreted to be a nonspecific transitory response to protein (not PBS). None of the other cytokines was induced by PA or LF (data not shown). The significantly higher induction and extended course of response beyond 6 hours in LT-treated mice indicate that induction is specific to active toxin in the BALB/cJ mice.

\section{LT effects on VEGF expression}

VEGF has been associated with increased vascular permeability in the lungs $(35,36)$ and other organs $(37)$ and is induced by hypoxia (38). Pleural effusions associated with mortality in both mouse strains led to careful examination of this cytokine. VEGF was not induced in liver, spleen, or lung tissues of LT-treated mice analyzed by RPA and Western blot. Immunostaining of lungs also revealed no local increase in VEGF expression (data not shown).

Role of FasL in LT-mediated mortality and hepatic injury in mice

Hepatocytes are sensitive to programmed cell death, and Fas/FasL apoptosis pathways play a major role in liver pathology in numerous diseases (39). Polymorphisms between C57BL/6 and BALB/c mice affect specific activity of FasL, with higher cytotoxic function associated with the BALB/c strain (40). Although LTinduced FasL (Table 1) and soluble FasL were measurable in the sera of BALB/cJ mice (Figure 10a), LTtreated FasL-deficient (gld) mice exhibited a mortality 

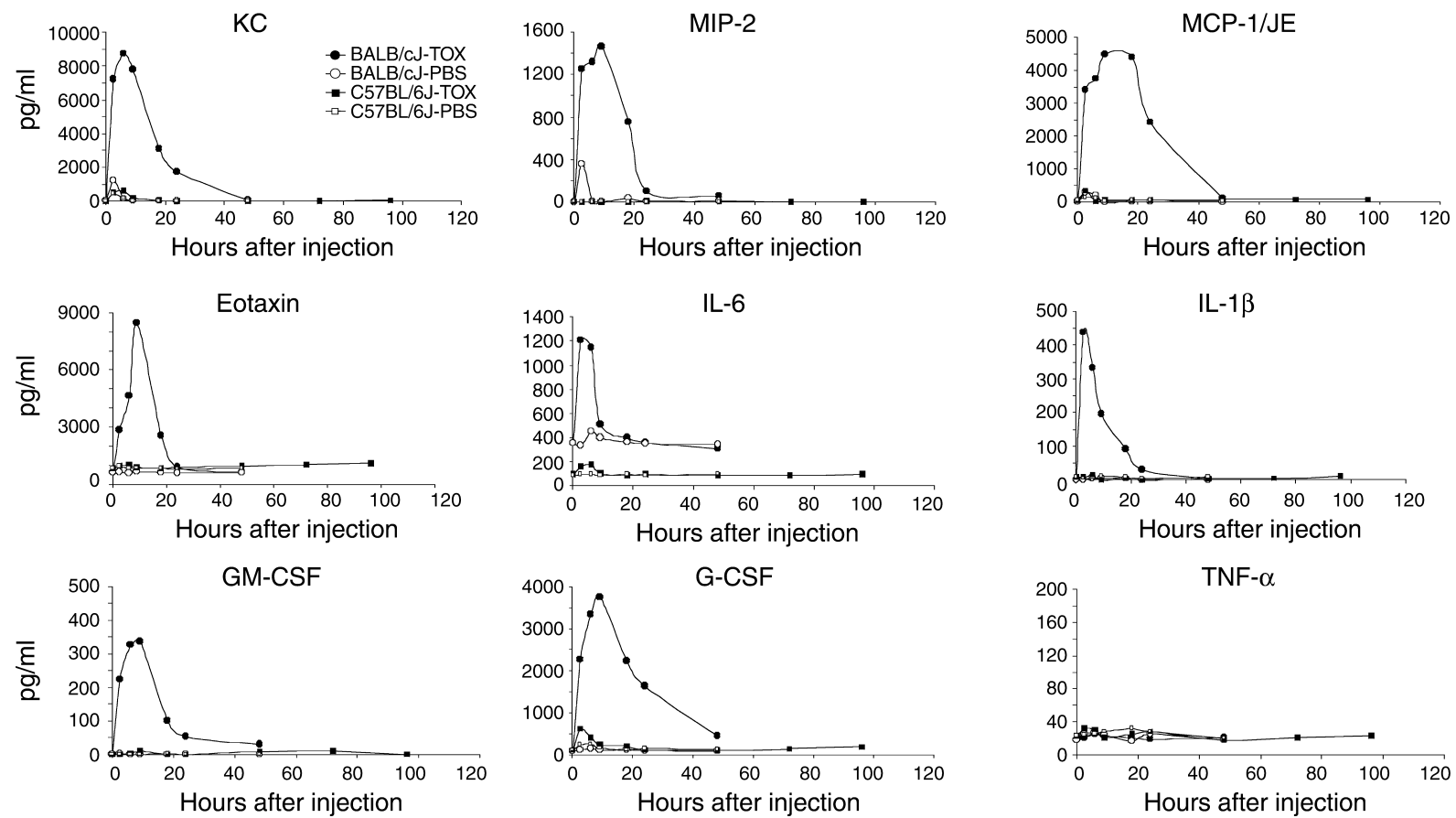

\section{Figure 9}

Time course of serum cytokine protein levels after LT treatment. Mice were injected i.p. with $1.0 \mathrm{ml}$ of PBS or LT (TOX; $100 \mu \mathrm{g}$ PA + $100 \mu \mathrm{g}$ LF). ELISA determinations were done on sera pooled from three to five mice for each time point and treatment.

curve (Figure 10b) and pleural cavity fluid accumulation (data not shown) similar to those of their $\mathrm{BALB} / \mathrm{cJ}$ counterparts, indicating that LT cytotoxicity does not require FasL function. Lack of LT-mediated FasL induction in C57BL/6J mice supports this result (data not shown).

\section{LT induction of cytokines from isolated macrophages}

Previous studies have reported cytokine production from macrophages in response to sub-lytic doses of LT $(18,41$, 42). BALB/cJ macrophages are extremely sensitive, with $100 \%$ of cells dying $90-120$ minutes after treatment with $200 \mathrm{ng} / \mathrm{ml}$ of LT, while C57BL/6J macrophages are resistant, with $100 \%$ surviving at 6 hours after treatment with $2,000 \mathrm{ng} / \mathrm{ml}$ toxin (data not shown). BALB/cJ peritoneal macrophages and RAW264.7 cells (a sensitive macrophage cell line) treated with $10 \mathrm{pg} / \mathrm{ml}$ (sub-lytic) to 1,000 $\mathrm{ng} / \mathrm{ml}$ (lytic) of LT for 90 minutes, 120 minutes, or 6 hours, as well as culture supernatants, were tested for production of the cytokines shown in Figure 9. RAW264.7 cells (with or without toxin treatment) constitutively produced a high level of MCP-1/JE $(4,500$ $\mathrm{pg} / \mathrm{ml}$ ), which was not altered by LT treatment. None of the other factors was induced in LT-treated RAW264.7 cells or peritoneal macrophages (data not shown). A twofold increase in IL- $1 \beta$ levels was noted, but only at the highest (lytic) concentrations of toxin in BALB/cJ macrophages, and never in RAW264.7 cells (data not shown). Therefore, sensitive macrophages alone appear not to be the source of the LT-induced factors.

\section{In situ analysis of $\mathrm{KC}$ production}

Of the cytokines analyzed, the chemokine KC had the greatest RNA and protein response levels and was the only factor induced in both mouse strains (Figure 8c). $\mathrm{KC}$ is a potent neutrophil recruiter, and massive neutrophilia was associated with LT treatment in both strains (Figure 2). This factor was not induced by LT treatment of in vitro macrophages from either mouse strain. To identify a cellular source in vivo, we performed in situ analysis of KC expression and confirmed the impressive induction of this chemokine in spleen and liver of LT-treated BALB/cJ mice at 2.5 hours (Figure 11a) and 6 hours (Figure 11b). No expression remained at 24 hours (Figure 11c), and no expression was seen in PBS-injected controls (data not shown). By comparison, minimal $\mathrm{KC}$ was evident at 6 hours in C57BL/6J mice (Figure 11d). The diffuse high expression seen throughout the liver of the $\mathrm{BALB} / \mathrm{cJ}$ mice at 2.5 hours and 6 hours was associated with hepatocytes and not Kupffer or endothelial cells (Figure 11e). KC expression decreased when hepatic necrosis began (data not shown). Autoradiographic analysis of the spleen sections (Figure 11, $\mathrm{f}-\mathrm{h}$ ) revealed KC expression in the marginal zone, follicular dendritic cells, and red pulp. LT induction of $\mathrm{KC}$ in hepatocytes at such early time points, prior to appearance of hypoxia or liver damage, presents, to our knowledge, the first report of the toxin directly affecting this cell type and introduces a potentially new direct target for LT-mediated effects. 

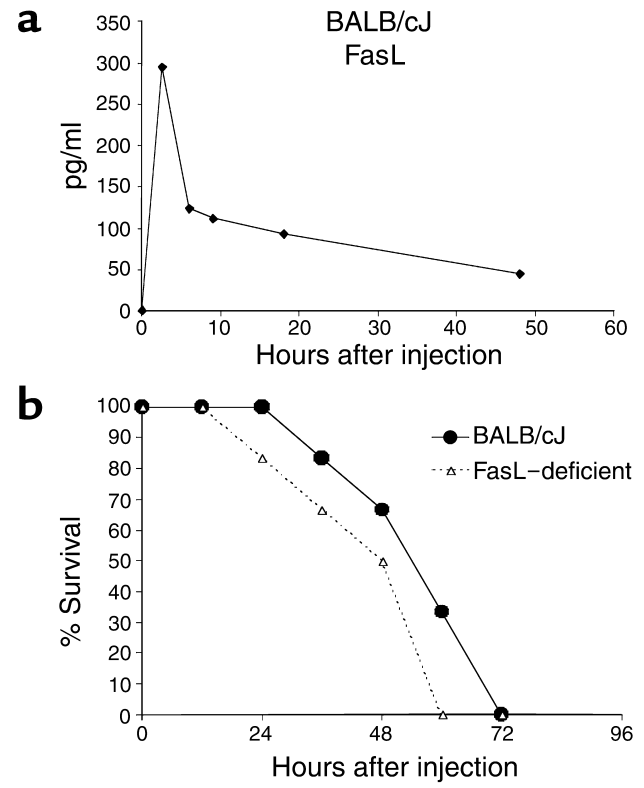

\section{Discussion}

In this study, events leading to LT-induced death of $\mathrm{BALB} / \mathrm{cJ}$ and $\mathrm{C} 57 \mathrm{BL} / 6 \mathrm{~J}$ mouse strains were analyzed in detail. Despite harboring toxin-sensitive and resistant macrophages, both strains are susceptible to anthrax infection $(17,25)$ and, as reported here, to LT. BALB/cJ mice succumb more rapidly, but both strains experience a similar course of disease, with hypoxia-mediated necrosis of liver and metaphyseal bone marrow as hallmarks of crisis, accompanied by pleural effusions. Contrary to previous hypotheses (18), hallmarks of cytokine-induced shock such as inflammation, fibrin clots and associated thrombosis, DIC, neutrophil margination and associated endothelial cell damage, renal dysfunction, and TNF- $\alpha$ production are absent in LT-treated mice. Despite an early transitory production of other cytokines in BALB/cJ, no inflammatory cascade develops. C57BL/6J, which do not mount this response, display similar although delayed pathology and subse-

\footnotetext{
Figure 11

Induction of $K C$ in spleen and liver analyzed by in situ hybridization. $\mathrm{BALB} / \mathrm{cJ}$ or C57BL/6J mice were injected i.p. with $100 \mu \mathrm{g}$ LT. Spleens and livers were harvested at 2.5, 6, 24, or 36 hours after injection for in situ analysis of KC production. (a-c) Whole-organ-section phosphorimages of sense ( $\mathrm{s}$; control) and antisense (as) ${ }^{35} \mathrm{~S} \mathrm{KC}$ probe hybridization to BALB/c) spleen and liver at 2.5 hours (a), 6 hours (b), and 24 hours (c). (d) Sections of C57BL/6J mouse organs at 6 hours after LT. Arrows in a-d indicate the single spleen section in each panel; all other sections are liver. Red signifies the highest intensity of signal, while bluish-green is negative background. (e-h) Silver-grain densities in various regions of each organ. (e) High clustering of grains at liver hepatocytes, with little association with endothelial cells (EC). (f) Higher expression in the spleen marginal zone $(\mathrm{MZ})$ in contrast to white pulp (W). (g) A dark-field image similarly showing the higher silver-grain densities associated with marginal zone (MZ), red pulp (R), and follicular dendritic cells (FDC). (h) High density of silver grains at the FDCs of the white pulp.
}

\section{Figure 10}

LT induction of FasL and cytotoxicity in FasL-deficient mice. (a) $\mathrm{BALB} / \mathrm{cJ}$ mice were treated i.p. with $100 \mu \mathrm{g} L T$, and ELISA determinations were done on sera pooled from three mice for each time point. (b) BALB/cJ $(n=6)$ or FasL-deficient $(n=6)$ mice were injected i.p. with $100 \mu \mathrm{g} L T$, and time to death was recorded for each strain.

quent death. The data indicate that LT induces hypoxia-mediated tissue damage and cytokine-independent death with shocklike manifestations. Macrophage lysis is not essential for LT-mediated death.

The cause of the more rapid onset of pathology in the $\mathrm{BALB} / \mathrm{cJ}$ mice is unclear. The rapid lysis of their macrophages with accompanying cytokine response may increase the rate of LT-mediated events but is clearly not required for the hypoxia, liver necrosis, pleural effusions, and mortality seen in both strains. The cytokine burst is not necessarily linked to macrophage lysis, although the rapid release of IL-1 $\beta$, as early as 150 minutes, probably reflects release of intracellular stores concomitant with lysis, since induction of IL-1 $\beta$ mRNA is not observed. Transitory production of other cytokines could be a response of various cells to IL-1 $\beta$ (43-47). The remarkable production of eotaxin and the $\mathrm{KC}$ induction in hepatocytes confirm involvement of other cell types and at the same
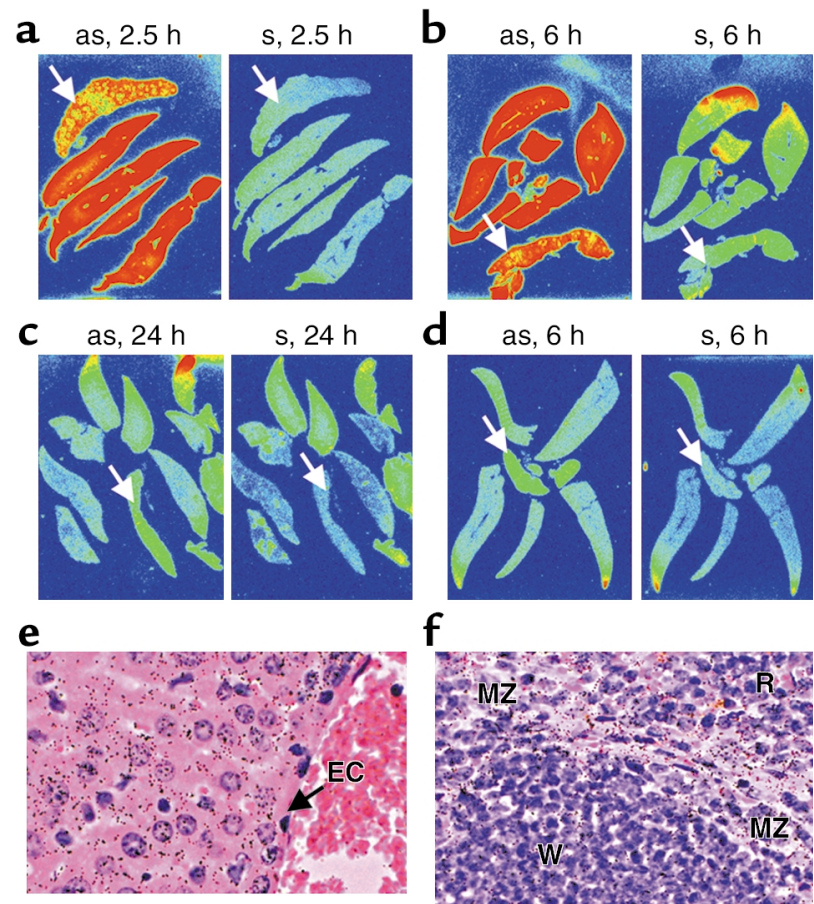

g
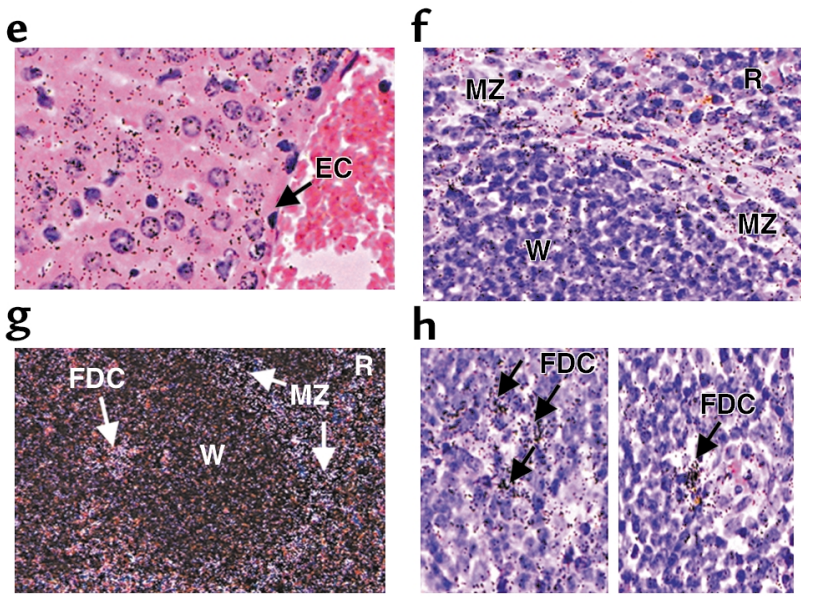

h

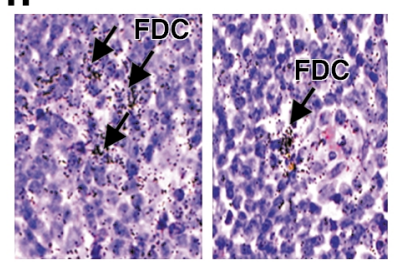


time support a requirement for macrophage lysis, since hepatocytes are expected to be equally sensitive in both mice. C57BL/6J macrophages are not defective in normal cytokine responses to other insults $(48,49)$.

Immunological differences between BALB/c and $\mathrm{C} 57 \mathrm{BL} / 6$ in sensitivity and resistance to a variety of bacterial, parasitic, and fungal infections have often been linked to Th1/Th2 responses (50-52). However, classic Th1/Th2 cytokines, and those involved in their regulation (IL-12, IL-4, IFN- $\gamma$, etc.), are not induced by LT, nor are inflammation or traditional responses associated with IL-1 $\beta$ and IL- 6 observed. It is therefore difficult to link the exacerbation of LT toxicity in BALB/cJ mice to these or other induced cytokines (MCP-1/JE, eotaxin, GM-CSF, etc.). Strain differences in FasL (40) and NO production by macrophages $(53,54)$ are also not involved in LT susceptibility (experiments with iNOS knockout mice; data not shown). Ultimately the difference between these strains may lie not in the brief cytokine response seen in BALB/cJ, but in the induction of a protective response in $\mathrm{C} 57 \mathrm{BL} / 6 \mathrm{~J}$, such as the LT-mediated IL-15 induction.

The difference in LT susceptibility between the two strains may not be linked to immune responses. Potential strain differences might include the number of toxin receptors. Although macrophages from both strains internalized LT and showed cleavage of MAPKK proteins with similar kinetics (data not shown), it is not known whether an equivalent number of toxin receptors exist on all tissues. Additional genetic differences could result in differential resistance at a variety of levels, ranging from neuroendocrine control of vascular barrier function to general stress response by undefined molecular mechanisms. Documented differences in the response of these two strains to neural and hormonal elements $(55,56)$ could have consequences for pathological cascades. These differences need not correlate with downstream effects on cytokine function (57). The higher resistance of C57BL/6 mice to hypoxic insult may provide an even simpler explanation for their delayed death $(58,59)$.

Regardless of the mechanism of cytokine response in LT-treated BALB/cJ mice, and its possible role in pathology in this strain, neither macrophage lysis nor this response is required for LT-induced lethality in mice. Our findings confirm that LT does not induce TNF- $\alpha$ in LT-sensitive mouse macrophages (19). The lack of a sustained cytokine response is consistent with LT-mediated shutdown of MAPK signaling $(20,21)$. Despite the extensive emphasis given to the role of macrophage lysis in LT effects in anthrax (18), the lack of a requirement for macrophage lysis is not surprising, given that lysis occurs only in a limited subset of inbred mice. Human, rat, and many LT-sensitive mouse strain macrophages are resistant to LT (data not shown).

Death induced by LT in mice may relate to liver necrosis accompanied by pleural effusions. Hypoxia is clearly involved in the tissue necrosis. The histopathological observations in LT-treated mice, including hepatic centrilobular coagulative necrosis, metaphyseal bone marrow necrosis, and infarction-like necrosis of the incisor dental pulp (data not shown), are indicative of hypoxic tissue death. Hypoxia-marker analyses at the organ level and high levels of EPO in blood confirm LT-induced hypoxia. Hypoxia and tissue damage are accompanied by pleural effusion, ascites, and congestion and edema of the extremities, all generic indicators of circulatory collapse. Whether hypoxia-linked tissue necrosis is the primary event leading to a secondary vascular leakage and shocklike symptoms or is itself a result of circular insufficiency due to LT effects on vascular function is unknown.

Vascular dysfunction and thrombosis have been described in association with anthrax infection in humans $(9,60)$ and animals (60-64). This type of classic vasculitis induced by endothelial adherence of inflammatory cells and fibrinoid necrosis of vessels did not occur in LT-treated mice, despite similar accumulation of pleural fluid in human anthrax subjects, animal models $(2,9,11,14,65,66)$, and LT-treated mice. LT induction of shock by interference with endothelial cell function has been proposed $(2,7,63,64)$, but no evidence of direct LT effects on endothelium has been presented. If vascular collapse occurs in LT-treated mice, it is quite different from that associated with endotoxic shock. Thrombocytopenia is present in 50\% of LT-treated mice without evidence of thrombosis. Although often associated with consumptive coagulative dysfunction (i.e., DIC), thrombocytopenia may also be caused by direct platelet destruction, megakaryocyte loss or dysfunction, or hypoxia. Drugs can induce rapid thrombocytopenia without initial coagulative pathologies $(67,68)$. Additionally, there are examples of thrombosis-independent shock processes, such as the Hantavirus pulmonary syndrome (HPS), which manifests thrombocytopenia without coagulopathy. The pathology of HPS is intriguingly similar to that of LT: pulmonary effusions without histological changes in the lungs, neutrophilia, hypoalbuminemia, increased AST or ALT, no changes in renal or cardiac function, and no coagulation, but striking vascular leakage and multiorgan failure $(69,70)$.

An alternative hypothesis of LT-mediated toxicity is that LT induces hypoxia directly and the observed vascular leakage is secondary to tissue necrosis, rather than the cause of it. LT may interfere with metabolic pathways that prevent proper delivery of oxygen, or its utilization in tissues. As a consequence, extensive liver necrosis and subsequent hypoalbuminemia, with resulting decreased oncotic pressure, may drive the transudative pleural effusion seen in LT-treated mice. The later appearance of pleural fluid in LT-treated mice supports this hypothesis.

LT-treated mice show marked neutrophilia with no recruitment of these cells into any tissues. High neutrophil numbers have been previously reported with respiratory anthrax $(3,5,11,14,71,72)$ and are often associated with bacterial infections, but LT injection 
alone appears to induce massive release of the potent neutrophil-recruitment and -activation mediators MIP- 2 and KC (which are similar to the IL- 8 and GRO chemokines in humans). Exposure of neutrophils to LT has been shown to increase their chemotactic response to other substances (73). LT may also prevent proper passage of activated recruited neutrophils into tissues. A previous report indicates direct LT interference with P-selectin expression on BALB/cJ platelets in vitro (74). Preliminary studies indicate that LT induces the shedding of selectin molecules into the circulation (data not shown), and this could negatively impact neutrophil adhesion and traversal. Intravascular aggregation of activated neutrophils with subsequent release of reactive oxygen species and potent enzymes may play a role in tissue damage (75).

The detailed analysis of LT-mediated toxicity in mice presented here advances our understanding of anthrax pathogenesis. The similarities in the pathology induced by LT and by anthrax infection point to the importance of understanding how the toxin acts during infection. Further deciphering of the molecular events by which the toxin contributes to pathogenesis is a crucial next step in the study of anthrax. The mechanism linking LT proteolytic function to the in vivo pathogenesis that involves hypoxia and vascular dysfunction remains to be elucidated.

\section{Acknowledgments}

We thank Jerrold Ward for valuable discussions, help with in situ analyses, figures, and critical reading of the manuscript; Thomas J. Sayers for the generous gift of mice; Nick Duesbery, Nathaniel Martinez, Jason Wiggins, Ramakrishnan Sitaraman, and Shihui Liu for critical reading of the manuscript; Dee Green, Scott Lawrence, and Keith Rogers for help with necropsies and tissue preparation; Kelly Parman for help with immunohistochemistry; Cecil Fox for help with in situ hybridization experiments; and Dana Hsu for toxin preparation. This work is supported, in part, by federal funds from the National Cancer Institute under contract NO1-CO12400 to Science Applications International Corporation Frederick. The content of this publication does not necessarily reflect the views or policies of the Department of Health and Human Services, nor does mention of trade names, commercial products, or organizations imply endorsement by the US government.

1. Leppla, S.H. 1999. The bifactorial Bacillus anthracis lethal and oedema toxins. In Comprehensive sourcebook of bacterial protein toxins. J.E. Alouf and J.H. Freer, editors. Academic Press. London, United Kingdom. 243-263.

2. Beall, F.A., and Dalldorf, F.G. 1966. The pathogenesis of the lethal effect of anthrax toxin in the rat. J. Infect. Dis. 116:377-389.

3. Fish, D.C., Klein, F., Lincoln, R.E., Walker, J.S., and Dobbs, J.P. 1968. Pathophysiological changes in the rat associated with anthrax toxin. J. Infect. Dis. 118:114-124.

4. Klein, F., Hodges, D.R., Mahlandt, B.G., Jones, W.I., and Lincoln, R. 1962. Anthrax toxin: causative agent in the death of Rhesus monkeys. Science. 138:1331-1333.

5. Klein, F., et al. 1966. Pathophysiology of anthrax. J. Infect. Dis. 116:123-138.

6. Beall, F.A., Taylor, M.J., and Thorne, C.B. 1962. Rapid lethal effect in rats of a third component found upon fractionating the toxin of Bacillus anthracis. J. Bacteriol. 83:1274-1280.

7. Smith, H., and Stoner, H.B. 1967. Anthrax toxic complex. Fed. Proc 26:1554-1557.

8. Ezzell, J.W., Ivins, B.E., and Leppla, S.H. 1984. Immunoelectrophoretic analysis, toxicity, and kinetics of in vitro production of the protective antigen and lethal factor components of Bacillus anthracis toxin. Infect. Immun. 45:761-767.

9. Abramova, F.A., Grinberg, L.M., Yampolskaya, O.V., and Walker, D.H. 1993. Pathology of inhalational anthrax in 42 cases from the Sverdlovsk outbreak of 1979. Proc. Natl. Acad. Sci. U. S. A. 90:2291-2294.

10. Borio, L., et al. 2001. Death due to bioterrorism-related inhalational anthrax: report of 2 patients. JAMA. 286:2554-2559.

11. Jernigan, J.A., et al. 2001. Bioterrorism-related inhalational anthrax: the first 10 cases reported in the United States. Emerg. Infect. Dis. 7:933-944.

12. Mayer, T.A., et al. 2001. Clinical presentation of inhalational anthrax following bioterrorism exposure: report of 2 surviving patients. JAMA. 286:2549-2553.

13. Earls, J.P., et al. 2002. Inhalational anthrax after bioterrorism exposure: spectrum of imaging findings in two surviving patients. Radiology. 222:305-312

14. Brachman, P.S. 1980. Inhalation anthrax. Ann. N. Y. Acad. Sci. 353:83-93.

15. Pezard, C., Duflot, E., and Mock, M. 1993. Construction of Bacillus anthracis mutant strains producing a single toxin component. J. Gen. Microbiol. 139:2459-2463.

16. Pezard, C., Berche, P., and Mock, M. 1991. Contribution of individual toxin components to virulence of Bacillus anthracis. Infect. Immun. 59:3472-3477.

17. Welkos, S.L., Keener, T.J., and Gibbs, P.H. 1986. Differences in susceptibility of inbred mice to Bacillus anthracis. Infect. Immun. 51:795-800.

18. Hanna, P.C., Acosta, D., and Collier, R.J. 1993. On the role of macrophages in anthrax. Proc. Natl. Acad. Sci. U. S. A. 90:10198-10201.

19. Erwin, J.L., et al. 2001. Macrophage-derived cell lines do not express proinflammatory cytokines after exposure to Bacillus anthracis lethal toxin. Infect. Immun. 69:1175-1177.

20. Pellizzari, R., Guidi-Rontani, C., Vitale, G., Mock, M., and Montecucco, C. 1999. Anthrax lethal factor cleaves MKK3 in macrophages and inhibits the LPS/IFNgamma-induced release of NO and TNFalpha. FEBS Lett. 462:199-204.

21. Pellizzari, R., Guidi-Rontani, C., Vitale, G., Mock, M., and Montecucco, C. 2000. Lethal factor of Bacillus anthracis cleaves the N-terminus of MAPKKs: analysis of the intracellular consequences in macrophages. Int. J. Med. Microbiol. 290:421-427.

22. Duesbery, N.S., et al. 1998. Proteolytic inactivation of MAP-kinasekinase by anthrax lethal factor. Science. 280:734-737.

23. Vitale, G., et al. 1998. Anthrax lethal factor cleaves the N-terminus of MAPKKs and induces tyrosine/threonine phosphorylation of MAPKs in cultured macrophages. Biochem. Biophys. Res. Commun. 248:706-711.

24. Vitale, G., Bernardi, L., Napolitani, G., Mock, M., and Montecucco, C. 2000. Susceptibility of mitogen-activated protein kinase kinase family members to proteolysis by anthrax lethal factor. Biochem. J. 352:739-745.

25. Kalns, J., et al. 2002. TNF receptor 1, IL-1 receptor, and iNOS genetic knockout mice are not protected from anthrax infection. Biochem. Biophys. Res. Commun. 292:41-44.

26. Bunner, D.L., Morris, E.R., and Mereish, K.A. 1993. Effects of anthrax toxin (protective antigen and lethal factor) on human monocytes and polymorphonuclear leukocytes. In Vitro Toxicology. 6:81-89.

27. Varughese, M., et al. 1998. Internalization of a Bacillus anthracis protective antigen-c-Myc fusion protein mediated by cell surface anti-c-Myc antibodies. Mol. Med. 4:87-95.

28. Klimpel, K.R., Arora, N., and Leppla, S.H. 1994. Anthrax toxin lethal factor contains a zinc metalloprotease consensus sequence which is required for lethal toxin activity. Mol. Microbiol. 13:1093-1100.

29. Hoover, S.B., Sung, C., Cottler-Fox, M.H., and Fox, C.H. 2000. In situ hybridization techniques for studying gene expression in the genetically altered mouse. In Pathology of genetically engineered mice. J.M. Ward, J.F. Mahler, R.R. Maronpot, and J.P. Sundberg, editors. Iowa State University Press. Ames, Iowa, USA. 13-22.

30. Roberts, J.E., Watters, J.W., Ballard, J.D., and Dietrich, W.F. 1998. Ltx1, a mouse locus that influences the susceptibility of macrophages to cytolysis caused by intoxication with Bacillus anthracis lethal factor, maps to chromosome 11. Mol. Microbiol. 29:581-591.

31. Lacombe, C., and Mayeux, P. 1998. Biology of erythropoietin. Haematologica. 83:724-732.

32. Hoetzel, A., et al. 2001. Effect of nitric oxide on shock-induced hepatic heme oxygenase-1 expression in the rat. Hepatology. 33:925-937.

33. Benjamin, I.J., Kroger, B., and Williams, R.S. 1990 . Activation of the heat shock transcription factor by hypoxia in mammalian cells. Proc. Natl. Acad. Sci. U. S. A. 87:6263-6267.

34. Lee, P.J., et al. 1997. Hypoxia-inducible factor-1 mediates transcriptional activation of the heme oxygenase- 1 gene in response to hypoxia. J. Biol. Chem. 272:5375-5381.

35. Kaner, R.J., et al. 2000. Lung overexpression of the vascular endothelial 
growth factor gene induces pulmonary edema. Am. J. Respir. Cell Mol. Biol. 22:657-664.

36. Grove, C.S., and Lee, Y.C. 2002. Vascular endothelial growth factor: the key mediator in pleural effusion formation. Curr. Opin. Pulm. Med. 8:294-301.

37. Bates, D.O., Hillman, N.J., Williams, B., Neal, C.R., and Pocock, T.M. 2002. Regulation of microvascular permeability by vascular endothelial growth factors. J. Anat. 200:581-597.

38. Forsythe, J.A., et al. 1996. Activation of vascular endothelial growth factor gene transcription by hypoxia-inducible factor 1 . Mol. Cell. Biol. 16:4604-4613.

39. Pinkoski, M.J., Brunner, T., Green, D.R., and Lin, T. 2000. Fas and Fas ligand in gut and liver. Am. J. Physiol. Gastrointest. Liver Physiol. 278:G354-G366.

40. Kayagaki, N., et al. 1997. Polymorphism of murine Fas ligand that affects the biological activity. Proc. Natl. Acad. Sci. U. S. A. 94:3914-3919.

41. Hanna, P.C., Kruskal, B.A., Ezekowitz, R.A., Bloom, B.R., and Collier, R.J. 1994. Role of macrophage oxidative burst in the action of anthrax lethal toxin. Mol. Med. 1:7-18.

42. Kalns, J., Morris, J., Eggers, J., and Kiel, J. 2002. Delayed treatment with doxycycline has limited effect on anthrax infection in BLK57/B6 mice. Biochem. Biophys. Res. Commun. 297:506-509.

43. Mahalingam, S., and Karupiah, G. 1999. Chemokines and chemokine receptors in infectious diseases. Immunol. Cell Biol. 77:469-475.

44. Calkins, C.M., et al. 2002. IL-1 regulates in vivo C-X-C chemokine induction and neutrophil sequestration following endotoxemia. J. Endotoxin Res. 8:59-67.

45. Sica, A., et al. 1990. IL-1 transcriptionally activates the neutrophil chemotactic factor/IL-8 gene in endothelial cells. Immunology. 69:548-553.

46. Sironi, M., et al. 1989. IL-1 stimulates IL-6 production in endothelial cells. J. Immunol. 142:549-553.

47. Mantovani, A., Locati, M., Allavena, P., and Sozzani, S. 1996. The chemokine superfamily: crosstalk with the IL-1 system. Immunobiology. 195:522-549.

48. Beezhold, D.H., Best, G.K., Bonventre, P.F., and Thompson, M. 1989. Endotoxin enhancement of toxic shock syndrome toxin 1-induced secretion of interleukin 1 by murine macrophages. Rev. Infect. Dis. 11(Suppl. 1):S289-S293

49. Kovacs, E.J., Radzioch, D., Young, H.A., and Varesio, L. 1988. Differential inhibition of IL-1 and TNF-alpha mRNA expression by agents which block second messenger pathways in murine macrophages. J. Immunol. 141:3101-3105.

50. Heinzel, F.P., Sadick, M.D., Mutha, S.S., and Locksley, R.M. 1991. Production of interferon gamma, interleukin 2, interleukin 4, and interleukin 10 by $\mathrm{CD} 4+$ lymphocytes in vivo during healing and progressive murine leishmaniasis. Proc. Natl. Acad. Sci. U. S. A. 88:7011-7015.

51. Szeliga, J., Fiuk, D., Walencka, M., and Goscicka, T. 1997. Interleukin 12 and direct cytotoxicity of spleen lymphocytes to Listeria innocua-phagocyting syngeneic macrophages in C57BL/6 and BALB/c mice. Arch. Immunol. Ther. Exp. (Warsz.). 45:49-54.

52. Autenrieth, I.B., Beer, M., Bohn, E., Kaufmann, S.H., and Heesemann, J. 1994. Immune responses to Yersinia enterocolitica in susceptible BALB/C and resistant C57BL/ 6 mice: an essential role for gamma interferon. Infect. Immun. 62:2590-2599.

53. Stenger, S., Thuring, H., Rollinghoff, M., and Bogdan, C. 1994. Tissue expression of inducible nitric oxide synthase is closely associated with resistance to Leishmania major. J. Exp. Med. 180:783-793.
54. Kaushik, R.S., Uzonna, J.E., Gordon, J.R., and Tabel, H. 1999. Innate resistance to Trypanosoma congolense infections: differential production of nitric oxide by macrophages from susceptible BALB/c and resistant C57Bl/6 mice. Exp. Parasitol. 92:131-143.

55. Shanks, N., Griffiths, J., and Anisman, H. 1994. Norepinephrine and serotonin alterations following chronic stressor exposure: mouse strain differences. Pharmacol. Biochem. Behav. 49:57-65.

56. Shanks, N., Griffiths, J., Zalcman, S., Zacharko, R.M., and Anisman, H. 1990. Mouse strain differences in plasma corticosterone following uncontrollable footshock. Pharmacol. Biochem. Behav. 36:515-519.

57. Price, P., et al. 1996. Adrenalitis and the adrenocortical response of resistant and susceptible mice to acute murine cytomegalovirus infection. Eur. J. Clin. Invest. 26:811-819.

58. Bogdanov, N.N., and Soldatov, P.E. 1999. C57Bl/6 mice are more resistant to hypoxic hypoxia than BALB/c mice. Biull. Eksp. Biol. Med. 128:511-513.

59. Meerson, F.S., and Maizelis, M.I. 1973. Influence of adaptation hypoxia on the brain function and its resistance to noxious factors. Zh. Nevropatol. Psikbiatr. Im. S. S. Korsakova. 73:1414-1421.

60. Grinberg, L.M., Abramova, F.A., Yampolskaya, O.V., Walker, D.H., and Smith, J.H. 2001. Quantitative pathology of inhalational anthrax I: quantitative microscopic findings. Mod. Pathol. 14:482-495.

61. Rangel, R.A., and Gonzalez, D.A. 1975. Bacillus anthracis meningitis. Neurology. 25:525-530.

62. Pluot, M., et al. 1976. Anthrax meningitis. Report of two cases with autopsies. Acta Neuropathol. (Berl.). 36:339-345.

63. Dalldorf, F.G., and Beall, F.A. 1967. Capillary thrombosis as a cause of death in experimental anthrax. Arch. Pathol. 83:154-161.

64. Zaucha, G.M., Pitt, M.L., Estep, J., Ivins, B.E., and Friedlander, A.M. 1998. The pathology of experimental anthrax in rabbits exposed by inhalation and subcutaneous inoculation. Arch. Pathol. Lab. Med. 122:982-992.

65. Plotkin, S.A., Brachman, P.S., Utell, M., Bumford, F.H., and Atchison, M.M. 2002. An epidemic of inhalation anthrax, the first in the twentieth century. I. Clinical features. 1960. Am. J. Med. 112:4-12.

66. Gleiser, C.A. 1967. Pathology of anthrax infection in animal hosts. Fed. Proc. 26:1518-1521.

67. Aster, R.H. 1999. Drug-induced immune thrombocytopenia: an overview of pathogenesis. Semin. Hematol. 36:2-6.

68. Burgess, J.K. 2001. Molecular mechanisms of drug-induced thrombocytopenia. Curr. Opin. Hematol. 8:294-298.

69. Fernandez, G.E. 2001. Hantavirus. Prim. Care Update Ob Gyns. 8:53-58

70. Kanerva, M., Mustonen, J., and Vaheri, A. 1998. Pathogenesis of puumala and other hantavirus infections. Rev. Med. Virol. 8:67-86.

71. Dutz, W., Saidi, F., and Kohout, E. 1970. Gastric anthrax with massive ascites. Gut. 11:352-354.

72. Sirisanthana, T., Navachareon, N., Tharavichitkul, P., Sirisanthana, V., and Brown, A.E. 1984. Outbreak of oral-oropharyngeal anthrax: an unusual manifestation of human infection with Bacillus anthracis. Am. J. Trop. Med. Hyg. 33:144-150.

73. Wade, B.H., Wright, G.G., Hewlett, E.L., Leppla, S.H., and Mandell, G.L. 1985. Anthrax toxin components stimulate chemotaxis of human polymorphonuclear neutrophils. Proc. Soc. Exp. Biol. Med. 179:159-162.

74. Kau, J., et al. 2001. Platelet, the novel action target of anthrax. In 4th International Conference on Anthrax: Programs and Abstracts. Annapolis, Maryland, USA.

75. Lucchesi, B.R. 1994. Complement, neutrophils and free radicals: mediators of reperfusion injury. Arzneimittelforschung. 44:420-432. 